\title{
Práticas de Administração Financeira em Agroindústrias Familiares: Um estudo na região Noroeste do Rio Grande do Sul
}

\author{
Financial Management Practices in Family Agroindustries: A study in the \\ Northwest region of Rio Grande do Sul
}

\begin{abstract}
Darlan Ariel Prochnow Mestrando em Desenvolvimento Regional. Universidade Regional do Noroeste do Estado do Rio https://orcid.org/0000-0003-3699-074X Grande do Sul (UNIJUI) - Brasil. darlan.prochnow@sou.unijui.edu.br

Nelson José Thesing Doutor em Integração Regional. Universidade Regional do Noroeste do Estado do Rio Grande do https://orcid.org/0000-0001-7123-0717 Sul (UNIJUÍ) - Brasil. nelson.thesing@unijui.edu.br

Cleber Cervi Doutor em Administração. Instituto Federal de Educação, Ciência e Tecnologia do Rio Grande do https://orcid.org/0000-0002-3115-5078

Roberta Rodrigues Valandro

https://orcid.org/0000-0003-4142-3328

Sul (IFRS) - Brasil. cleber.cervi@veranopolis.ifrs.edu.br

Mestranda em Desenvolvimento Regional. Universidade Regional do Noroeste do Estado do Rio Grande do Sul (UNIJUÍ) - Brasil. roberta.valandro@sou.unijui.edu.br
\end{abstract}

\section{RESUMO}

A agroindústria familiar representa uma alternativa importante para um modelo de desenvolvimento rural e territorial. Contudo, são raros os estudos referentes a sua administração, especialmente em relação à área financeira. Considerando esta realidade, o presente estudo teve por objetivo investigar como são realizadas as práticas de administração financeira nas agroindústrias familiares do município de ljuí/RS. Os dados foram obtidos através de levantamento em 18 agroindústrias familiares e com a realização de duas entrevistas em profundidade. Constatou-se que os administradores das agroindústrias familiares pesquisadas são, em sua maioria, homens casados proprietários de pequenas áreas rurais. As ferramentas de gestão financeira mais utilizadas são o controle de contas a pagar e de receber, realizadas de forma manual na maioria dos casos. A análise dos ambientes macro, micro e interno da agroindústria familiar revelou a influência destes em sua administração financeira. Mesmo apresentando pontos de fragilidade na administração financeira, as agroindústrias familiares mostraram-se capazes de gerar renda às famílias e, por consequência, a melhoria das condições de vida no meio rural.

Palavras-chave: Agricultura familiar. Administração financeira. Gestão rural. Pluriatividade.

\section{ABSTRACT}

Family agroindustries represent an important alternative for a model of rural and territorial development. However, studies regarding its management are rare, especially in relation to the financial area. Considering this reality, the present study aimed to investigate how financial management practices are carried out in family agroindustries in the city of ljuí/RS. Data were obtained through a survey of 18 family agroindustries and two in-depth interviews. It was found that the administrators of the researched family agroindustries are, for the most part, married men who own small rural areas. The most used financial management tools are the control of accounts payable and receivable, carried out manually in most cases. The analysis of the macro, micro and internal environments of the family agroindustry revealed their influence on their financial management. Even with weak points in financial management, family agroindustries proved to be capable of generating income for families and, consequently, promote the improvement of living conditions in rural areas.

Keywords: family farming; financial management; rural management; pluriactivity. 


\section{INTRODUÇÃO}

Entre as formas de resistência e busca de alternativas para o desenvolvimento das regiões, as agroindústrias familiares vêm sendo constituídas em todo o país de forma crescente, de modo especial na região sul brasileira (KARNOPP et al., 2019). Deste modo, as agroindústrias familiares são uma alternativa para reverter as consequências sociais desfavoráveis no meio rural, impulsionando a criação de novas vagas de trabalho e gerando novas opções de fonte de renda aos agricultores familiares, dessa forma promovendo inclusão social e econômica. A transformação de uma matéria-prima bruta em algo mais elaborado agrega valor aos produtos. Assim, através da agroindústria familiar, o pequeno agricultor obtém renda superior comparada ao simples repasse de matéria-prima para as grandes agroindústrias (PREZOTTO, 2002). Por isso, a agroindustrialização constitui uma importante fonte de renda para as famílias rurais ao apresentar uma alternativa inovadora na arquitetura de redes agroalimentares (NIEDERLE; WESZ JUNIOR, 2009).

Como são, em sua maioria, agroindústrias de pequeno porte, as mesmas ficam expostas à enormes dificuldades em sua gestão, comprometendo a sua viabilidade. Essa situação pode se agravar, uma vez que estas organizações estão tipicamente localizadas em áreas periféricas quanto à produção de alimentos mais integrados aos mercados, em pequenas propriedades onde a mão de obra é estritamente familiar e, muitas vezes, com tecnologias defasadas, somado a outras dificuldades, como a infraestrutura de escoamento da produção e até mesmo o isolamento geográfico das unidades de produção (KARNOPP et al., 2019).

Deste modo, ao mesmo tempo em que se apontam vantagens com o desenvolvimento da agroindústria familiar, também se apontam dificuldades, como a cultura (racionalidade) dos agricultores, a falta de capacitação para o gerenciamento e a escassez de capital (ORSOLIN, 2006). De acordo com Wesz Júnior e Trentin (2005) a produção na agroindústria familiar é artesanal e pouco tecnológica. Além disso, a maioria das agroindústrias familiares não utiliza qualquer método de controle de custos (HAMANN et al., 2010).

Entre as dificuldades de gestão na agroindústria familiar, a administração financeira possui especial relevância, uma vez que as agroindústrias familiares apresentam baixa estrutura para o gerenciamento financeiro (GONZAGA et al., 2016). Desta forma, estudos que investiguem a administração financeira das agroindústrias familiares, especialmente relacionados aos aspectos contextuais e que ajudem a compreender a realidade e as perspectivas destes empreendimentos são importantes (GONZAGA et al., 2016; HAMANN et al., 2010).

Portanto, conhecer as práticas de administração financeira das agroindústrias familiares torna-se fundamental, especialmente ao se considerar o viés econômico deste empreendimento. Assim, o presente estudo teve como objetivo principal investigar como são realizadas as práticas de administração financeira nas agroindústrias familiares do município de ljuí, no estado do Rio Grande do Sul. Além disso, tratou-se de estabelecer o perfil das agroindústrias familiares e de seus administradores, bem como analisar a influência das variáveis ambientais na administração financeira das referidas agroindústrias.

Conforme dados da EMATER, as agroindústrias familiares de ljuí/RS geraram uma receita bruta aproximada de $\mathrm{R} \$ 4.520 .000,00$ no ano de 2019. Em 2011, o município de ljuí/RS possuía apenas três agroindústrias familiares com cadastro na EMATER. Hoje já existem 23 agroindústrias estabelecidas e outras estão em processo de legalização frente aos órgãos competentes. As famílias percebem nesse empreendimento uma oportunidade de aumentar a renda auferida na propriedade rural.

Para atender o objetivo proposto, este artigo está estruturado como segue. Primeiramente apresentase a fundamentação teórica, discutindo agroindústrias familiares e a importância da administração financeira nestes empreendimentos. Após, descreve-se os procedimentos metodológicos utilizados na pesquisa, na sequência, os resultados são descritos e analisados. Por fim, as considerações finais.

\section{FUNDAMENTAÇÃO TEÓRICA}

Esta seção contempla os conceitos fundamentais que envolvem o objeto de estudo. Primeiramente é apresentado o aporte teórico referente a agroindústria familiar e, após, a administração financeira nestes empreendimentos. 


\section{1 Agroindústria Familiar}

O tema da agroindustrialização por agricultores familiares é considerado recente na literatura, e começou a ser discutido em estudos clássicos, desenvolvidos no contexto do campesinato. Entre eles, os trabalhos de Kautsky (1980): A Questão Agrária e Lênin (1982): O Desenvolvimento do Capitalismo na Rússia. As principais contribuições literárias sobre a agroindústria familiar surgem após consideráveis transformações na agricultura, quando esse empreendimento passa a ganhar notoriedade como alternativa econômica aos pequenos agricultores familiares.

A partir dos anos 1970, as transformações de ordem técnico-produtiva e socioeconômica na agricultura vão se traduzir em uma redução considerável da autonomia das famílias rurais e, por consequência, a reprodução social se torna cada vez mais subordinada e dependente dos vínculos mercantis, ocorrendo ainda uma diferenciação social e produtiva entre os agricultores familiares (GAZOLLA; PELEGRINI, 2011).

Nos anos 1990, as transformações do meio rural continuaram e, devido à abertura comercial, ampliouse a internacionalização do mercado dos produtos agropecuários. Esse novo modelo de produção agravou a exclusão de um elevado contingente de produtores familiares (AMORIM; ESTADUTO, 2008). Wesz Junior, Trentin e Filippi (2009) descrevem como esse novo modelo de produção foi desfavorável aos pequenos agricultores.

Tem sido consenso entre os especialistas que o processo de modernização da agricultura acabou provocando bruscas mudanças no meio rural brasileiro. Se por um lado a alteração da base técnica incrementou a produção e a produtividade de muitos cultivares, em especial das commodities destinadas para a manutenção do modelo de crescimento econômico pautado nos mercados externos; por outro lado, acabou causando sérios problemas para a população que permanecia em pequenas propriedades e que não conseguiram se inserir na dinâmica implementada pela mecanização, quimificações e tecnificação das atividades agropecuárias (WESZ JÚNIOR; TRENTIN; FILIPPI, 2009, p. 10).

Considerando as mudanças no meio rural, um número expressivo de agricultores teve que procurar novas oportunidades, desenvolvendo estratégias para terem acesso a atividades estáveis e rentáveis, como a agroindústria familiar (AMORIM; ESTADUTO, 2008). Wesz Júnior e Trentin (2005) também afirmam que a agroindústria familiar representou uma alternativa aos agricultores familiares que não conseguiram se adequar ao sistema produtivo mais tecnológico.

Profeta et al. (2020) apontam que a criatividade e diversificação das atividades rurais viabiliza a permanência da população rural no campo em condições dignas de vida. Do mesmo modo Gazolla e Pelegrini (2011) entendem a agroindústria familiar como uma estratégia de reprodução social para a agricultura familiar, a qual deve ser desenvolvida para garantir uma vida digna aos pequenos agricultores.

Para fortalecer o desenvolvimento da agroindústria familiar, a legislação, seja Federal ou Estadual, traz a delimitação e objetivos desta atividade econômica. A Lei Federal no 11.326/2006 estabelece no Brasil as diretrizes para a formulação da Política Nacional da Agricultura Familiar e Empreendimentos Familiares Rurais. Nesta Lei o agricultor familiar e o empreendedor familiar rural são definidos como aqueles que praticam atividades no meio rural. Significa que estes não detêm área maior do que quatro módulos fiscais e que utilizam predominantemente mão de obra da própria família nas atividades econômicas (BRASIL, 2006).

A Lei $n^{\circ}$ 13.921, de 17 de janeiro de 2012, instituiu a Política Estadual de Agroindústria Familiar no estado do Rio Grande do Sul. Esta política tem por finalidade a agregação de valor à produção agropecuária, à atividade pesqueira e aquicultura e extrativista vegetal. Os objetivos são o desenvolvimento rural sustentável, a promoção da segurança alimentar e nutricional da população, e o incremento à geração de trabalho e renda (RIO GRANDE DO SUL, 2012a).

O Decreto Do Estado Do Rio Grande do Sul n 49.341 , de 05 de julho de 2012, cria o Programa Estadual de Agroindústria Familiar. A agroindústria familiar passa a ser o empreendimento de propriedade ou posse de agricultor (es) familiar (es) sob gestão individual ou coletiva, localizado em área rural ou urbana, com a finalidade de beneficiar e/ou transformar matérias-primas provenientes de explorações agrícolas, pecuárias, pesqueiras, aquícolas, extrativistas e florestais, abrangendo desde os processos simples até os mais complexos, como operações físicas, químicas e/ou biológicas (RIO GRANDE DO SUL, 2012b).

Para Mior (2005) a agroindústria familiar passa a ser uma forma de organização em que a família rural produz, processa e/ou transforma parte de sua produção agrícola e/ou pecuária, visando um processo de agregação de valor. $O$ processo de agroindustrialização pode ainda vir a ser um empreendimento associativo, reunindo uma ou várias famílias aparentadas ou não (MIOR, 2007).

A organização em forma associativa ou cooperativa garante alguns benefícios para a agroindústria familiar, como a otimização do espaço e do número de pessoas envolvidas, garantindo assim a reprodução de mais agricultores dentro de um mesmo espaço (WESZ JÚNIOR; TRENTIN, 2005). Todavia, o desenvolvimento 
da organização coletiva também depende de uma administração eficiente em todos os setores da agroindústria familiar.

Desta forma, todo processo de agroindustrialização desafia a administração, em cada um dos elementos do planejamento estratégico. Na área de gestão de pessoas, a mão de obra é da própria unidade familiar e, às vezes, conta com agricultores próximos. A remuneração passa a ser familiar, onde pode não haver uma clara divisão de remunerações entre os membros da família (WIVES; KUHN, 2018).

A produção trata-se da quantidade e o que produzir, além disso, de verificar o espaço disponível e público-alvo (quem irá consumir) (WIVES; KUHN, 2018). A matéria-prima que abastece a produção das agroindústrias familiares tem origem nos estabelecimentos dos agricultores proprietários e/ou associados a elas (ORSOLIN, 2006). Para agregar valor à matéria-prima e diferenciar os produtos, a forma artesanal ou colonial de produção deve estar estampada nos mesmos, demonstrando assim suas particularidades (WESZ JÚNIOR; TRENTIN, 2005).

O processo de agregação de valor inicia pela matéria-prima que abastece as agroindústrias, estas têm origem nos estabelecimentos dos agricultores proprietários e/ou associados a elas. Já o trabalho operacional, na maioria das vezes, é desenvolvido por familiares ou em alguns casos complementada com mão de obra contratada, geralmente de vizinhos. O gerenciamento é realizado pelos próprios agricultores. Dessa forma, os agricultores passam a atuar em toda a cadeia produtiva, até a colocação do produto no mercado (ORSOLIN, 2006).

A atuação dos familiares nos diversos setores da cadeia produtiva representa ampla interação com o ambiente interno da agroindústria familiar. Silva (2005) relata que o ambiente interno diz respeito à própria organização, composto pelos proprietários, empregados e administradores. Por outro lado, a família necessita da estreita relação como o microambiente, o qual é constituído pela agroindústria, seus clientes, concorrentes e entidades reguladoras (CHIAVENATO, 2003).

Diferentemente do microambiente, o macroambiente engloba as variáveis incontroláveis pela agroindústria familiar, formado pelos ambientes demográfico, econômico, sociocultural, natural, tecnológico e político-legal (KOTLER; KELLER, 2013). É necessária a busca constante de informações, para que assim seja possível aproveitar as oportunidades e prevenir-se das ameaças, uma vez que, no entendimento de Silva (2005) o desempenho administrativo é influenciado por diferentes forças, tanto de dentro como de fora da organização.

\subsection{Administração Financeira nas Agroindústrias Familiares}

A gestão da área de finanças é denominada de administração financeira. Para Gitman (2010), a administração financeira diz respeito às atribuições dos administradores financeiros nas organizações. Especificamente no meio rural, Crepaldi (2011, p. 39) afirma que "A administração financeira trata das decisões sobre planejamento a fim de atingir o objetivo de maximizar a riqueza dos proprietários rurais". Significa que as organizações, no contexto atual do mercado, necessitam da administração financeira, tornando-se uma área de grande importância para a sobrevivência das micro e pequenas empresas.

O modelo de agroindustrialização familiar é visto como uma alternativa para enfrentar as dificuldades enfrentadas pela agricultura familiar e impulsionar uma distribuição de renda mais equitativa. Pode assim proporcionar uma importante forma de inclusão social aos agricultores, melhorando sua qualidade de vida, mas para isso é necessária uma administração financeira competente. Neste sentido, é indispensável priorizar atividades que gerem renda às famílias e, mais do que isso, gerem baixos índices de poluição, preservação das culturas e tradições locais e a manutenção das pequenas propriedades rurais (PREZOTTO, 2002; WESZ JÚNIOR; TRENTIN; FILIPPI, 2009).

De acordo com Potrich, Grzybovski e Toebe (2017) as pequenas propriedades rurais apresentam problemas de sustentabilidade financeira, as quais residem na utilização de processo produtivo artesanal e pequena escala de produção, sendo que a agroindustrialização acaba sendo uma alternativa econômica para a geração de renda, mesmo em baixos volumes de produção. Para Lutke e Costa (2019) em meio às dificuldades de sustentabilidade financeira dos pequenos agricultores, as políticas públicas podem ser acessadas para iniciar ou fortalecer a agroindústria familiar.

As necessidades da família revelam ainda a importância do capital de giro, que segundo Gitman (2010), é comumente chamado de ativo circulante, e representa a porção do investimento que circula, de uma forma para outra, na condução dos negócios. De acordo com Wives e Kuhn (2018) esse é o montante de recursos necessário para o funcionamento da agroindústria familiar e compreende os recursos destinados à compra de insumos, matérias-primas, embalagens, energia, pagamentos de salários e despesas com frete para a entrega de produtos. 
A falta de capital de giro é indicada como uma das principais causas de falência de pequenas empresas. Este problema pode ser contornado pela agroindústria familiar, já que, como utiliza matéria-prima própria, parte significativa das receitas que seriam utilizadas como capital de giro se convertem em renda aos agricultores. No caso de dependência de matéria-prima externa, a agroindústria familiar teria a necessidade mensal de receitas no fluxo de caixa, para assim adquirir a sua matéria-prima de terceiros (PREZOTTO, 2002).

Em meio as dificuldades financeiras da agroindústria familiar, como a falta de capital de giro ou capital para investimentos, o crédito rural se torna uma alternativa eficaz na gestão financeira da agroindústria familiar. O Programa Nacional de Fortalecimento da Agricultura Familiar (Pronaf) disponibiliza linhas de crédito específicas para custeio e investimento em agroindústrias familiares. Portanto, o crédito rural assume papel de gerador de oportunidades e avanços tecnológicos na agricultura familiar (ZIGER, 2013).

Assim, as características da administração financeira são específicas do setor rural, no qual as agroindústrias familiares estão inseridas. Além de delimitar cada área ou setor da agroindústria familiar, é preciso separar o que é de consumo doméstico e o que é destinado à venda. Isso se torna uma questão fundamental para análise dos gastos e rendimentos do negócio. Já os custos e as despesas rurais possuem características próprias e referem-se aos gastos necessários para a operação da agroindústria familiar (WIVES; KUHN, 2018; HAMANN et al., 2010).

Deste modo, o processo de agroindustrialização está desafiado a contar com uma administração financeira eficiente, e mesmo que as micro e pequenas empresas da agricultura familiar aparentem uma gestão simplificada, na atualidade apresentam grande complexidade e exigem capacidade e preparo do administrador financeiro. A distribuição do fluxo financeiro exige desembolsos constantes ao longo dos processos de preparar a terra, semear, manter, colher e beneficiar, bem como na agroindustrialização, na manutenção e na conquista de mercados (ZANELLA; BARICHELLO, 2016).

Segundo Hamann et al. (2010) novos estudos devem ser realizados acerca da administração financeira das agroindústrias familiares, pois é necessário traçar o perfil delas, e pesquisas futuras podem abranger o ensino da contabilidade de custos nas agroindústrias familiares e, ainda, a relação entre renda e a utilização de sistemas de custos. Zanella e Barichello (2016) destacam a necessidade de estudos para entender o perfil dos gestores, assim como o uso das ferramentas de gestão financeira. Da mesma forma, Gonzaga et al. (2016) afirmam que o setor carece de estudos que revelem aspectos contextuais que ajudem a compreender a realidade e perspectivas da agroindústria familiar.

\section{METODOLOGIA}

Esta pesquisa classifica-se como exploratória e descritiva (GIL, 2014), com abordagem qualitativa e quantitativa (VERGARA, 2009; MINAYO; DESLANDES; GOMES, 2011). A coleta de dados dividiu-se em duas etapas. Na primeira etapa utilizou-se um questionário estruturado ou levantamento (MALHOTRA, 2011), desenvolvido para esta pesquisa, que é uma técnica de investigação composta por um conjunto de questões, submetidas a pessoas, definidas previamente com o propósito de obter informações sobre percepções, conhecimentos, comportamentos, entre outros (GIL, 2014).

Na segunda etapa utilizou-se a técnica de entrevistas em profundidade, a qual permite a interação entre o entrevistador e um único participante (COOPER; SCHINDLER, 2011). É importante destacar que a combinação entre pesquisa quanti e qualitativa traz benefícios para o estudo, pois "muitos pesquisadores reconhecem que a pesquisa qualitativa compensa a fraqueza da pesquisa quantitativa e vice-versa" (COOPER; SCHINDLER, 2011, p. 188).

O questionário utilizado na primeira etapa da pesquisa, de caráter quantitativo e descritivo, era composto por 37 questões, divididas em perguntas de múltipla escolha, em questões com resposta em escala do tipo Likert de 5 pontos ( 1 = Sem Importância; 5= Muito Importante), além de questões abertas com espaço para a resposta. Na primeira parte do questionário foram apresentadas as questões sobre a importância para a agroindústria familiar dos ambientes organizacionais, sendo que, para melhor entendimento, os ambientes foram detalhados (ex.: ambiente econômico = inflação, renda, preços, crédito etc.). Em seguida foram apresentadas as questões envolvendo a caracterização das agroindústrias familiares e de seus administradores. A segunda parte do questionário apresentava questões envolvendo a administração financeira do empreendimento.

A escolha da região pesquisada se deu a partir dos critérios de intencionalidade e acessibilidade (VERGARA, 2009). Desta forma, foram pesquisadas as agroindústrias familiares do município de ljuí, localizado na região noroeste do estado do Rio Grande do Sul. Para a definição da amostra da primeira etapa da pesquisa contatou-se a EMATER/RS para se conhecer a quantidade de agroindústrias familiares existentes no município de ljuí, sendo que a referida entidade apontou a existência de 23 agroindústrias familiares regularizadas frente aos órgãos competentes. Diante disso, convidou-se as 23 agroindústrias existentes no município para 
participarem da pesquisa. Entretanto, cinco delas não puderam ou não quiseram participar. Dessa forma, a amostra final resultou em 18 questionários, que foram respondidos pelos administradores das agroindústrias familiares.

Uma parte dos questionários foi distribuída aos respondentes na forma impressa, na localidade onde estão instaladas as agroindústrias familiares estudadas ou nas feiras onde elas comercializam seus produtos, os demais questionários foram enviados por e-mail. Os questionários foram tabulados em planilhas eletrônicas. Os dados quantitativos foram analisados através de análises estatísticas descritivas. Os dados obtidos pelas questões abertas foram analisados através da técnica de análise de conteúdo (BARDIN, 2011).

Após a realização da etapa descritiva, optou-se por realizar entrevistas em profundidade para compreender com maior clareza algumas das informações obtidas na primeira etapa da pesquisa. Portanto, as entrevistas em profundidade serviram para discutir e complementar os resultados obtidos pelo levantamento. Nessa etapa foram entrevistados um dos extensionistas da EMATER de ljuí/RS, o qual é responsável pela assistência técnica nas agroindústrias familiares do município, e o gestor da agroindústria familiar que afirmou não haver aumento na renda com a instalação deste empreendimento. O método de análise de dados utilizado nas entrevistas em profundidade foi a análise de conteúdo (BARDIN, 2011).

\section{DESCRIÇÃO E ANÁLISE DOS RESULTADOS}

Nesta seção são descritos e analisados os resultados da pesquisa. Inicialmente o perfil das agroindústrias familiares e de seus administradores. Após, as práticas de administração financeira nestes empreendimentos. Por fim, a influência das variáveis ambientais na administração financeira das agroindústrias familiares.

\subsection{Perfil das agroindústrias familiares e de seus administradores}

Nas agroindústrias pesquisadas, as propriedades rurais geralmente pertencem aos próprios agricultores, sendo que das 18 propriedades rurais 15 são próprias, uma é coletiva, uma é arrendada e uma é cedida. Resultado semelhante foi exposto na pesquisa de Amorim e Estaduto (2008), a qual apontou que 82,5\% das propriedades rurais onde as agroindústrias familiares estão instaladas pertencem aos agricultores. $O$ tamanho médio das propriedades em ljuí/RS é de, aproximadamente, nove hectares, sendo que a maior propriedade conta com 33 hectares e a menor possuí 0,5 hectare.

A mão de obra utilizada nas agroindústrias familiares investigadas é da própria família, com algumas exceções, como no caso de uma agroindústria que trabalha no formato de cooperativa, e, por isso, conta com empregados efetivos e/ou temporários, conforme a variação do volume de produção. De acordo com Prezotto (2002) essa é uma característica comum em agroindústrias familiares, onde a mão de obra utilizada é da própria família detentora do negócio, a qual atua tanto no setor primário, quanto no setor secundário da cadeia produtiva, contando eventualmente com a participação de agricultores próximos.

O pequeno tamanho das propriedades rurais foi considerado, por extensionista da EMATER, como motivo principal para a instalação da agroindústria familiar, justamente para agregar a renda que não é possível de se obter apenas com a venda de commodities, ou seja, com o produto sem transformação. Essa constatação já havia sido feita por Potrich, Grzybovski e Toebe $(2017$, p. 13) ao relatarem que "os agricultores industrializam sua produção nos formatos de agroindústrias, como é o caso do 'vinho, geleia e suco'. Assim fazendo, buscam por estratégias de sobrevivência".

Os administradores das agroindústrias familiares pesquisadas são predominantemente homens casados, cuja faixa etária é superior aos 41 anos em $67 \%$ dos casos. Na pesquisa de Zanella e Barichello (2016) em Chapecó/SC, constatou-se que $60 \%$ dos gestores de agroindústria familiar possuem entre 36 e 40 anos, ou seja, os administradores deste município são em média mais jovens do que os administradores de ljuí/RS. A Tabela 1 apresenta a caracterização das agroindústrias pesquisadas e de seus administradores.

Tabela 1 - Caracterização das agroindústrias familiares estudadas e de seus administradores

\begin{tabular}{cccc}
\hline Variáveis & Descrição & $\mathbf{N}$ & $\%$ \\
\hline \multirow{2}{*}{ Propriedade } & Própria & 15 & 83,35 \\
& Coletiva & 1 & 5,55 \\
& Arrendada & 1 & 5,55 \\
Tamanho & Cedida & 1 & 5,55 \\
& Até 5 Hectares & 9 & 50 \\
& De 6 até 10 Hectares & 2 & 11,11
\end{tabular}




\begin{tabular}{|c|c|c|c|}
\hline & De 11 até 15 Hectares & 4 & 22,22 \\
\hline & De 16 até 20 Hectares & 0 & 0 \\
\hline & Mais de 20 Hectares & 3 & 16,67 \\
\hline \multirow{2}{*}{ Mão de obra utilizada } & Própria família & 14 & 77,78 \\
\hline & Empregados contratados & 4 & 22,22 \\
\hline \multirow{2}{*}{ Gênero } & Masculino & 11 & 61,11 \\
\hline & Feminino & 7 & 38,89 \\
\hline \multirow{5}{*}{ Idade } & Menos de 21 anos & 0 & 0 \\
\hline & De 21 até 30 anos & 4 & 22,22 \\
\hline & De 31 até 40 anos & 2 & 11,11 \\
\hline & De 41 até 50 anos & 7 & 38,89 \\
\hline & 51 anos ou mais & 5 & 27,78 \\
\hline \multirow{5}{*}{ Estado Civil } & Solteiro (a) & 3 & 16,67 \\
\hline & Casado (a) & 13 & 72,23 \\
\hline & União Estável & 1 & 5,55 \\
\hline & Separado (a) / Divorciado (a) & 1 & 5,55 \\
\hline & Viúvo (a) & 0 & 0 \\
\hline \multirow{7}{*}{ Escolaridade } & Ensino Fundamental Incompleto & 3 & 16,67 \\
\hline & Ensino Fundamental Completo & 4 & 22,22 \\
\hline & Ensino Médio Incompleto & 1 & 5,55 \\
\hline & Ensino Médio Completo & 4 & 22,22 \\
\hline & Ensino Superior Incompleto & 2 & 11,11 \\
\hline & Ensino Superior Completo & 3 & 16,67 \\
\hline & Pós-Graduação & 1 & 5,55 \\
\hline
\end{tabular}

Nota: $\mathrm{N}=$ Número; \%: Percentual.

Fonte: Elaborado pelos autores (2019).

Quanto a escolaridade, apenas 22\% da amostra investigada apresentou ensino superior completo ou pós-graduação. Mesmo assim o percentual de administradores de agroindústrias familiares graduados é superior ao encontrado em Planaltina/DF por Hamann et al. (2010), onde apenas 6\% dos administradores apresentavam curso superior ou técnico concluído, e semelhante ao resultado encontrado em Chapecó/SC por Zanella e Barrichello (2016), onde 20\% dos administradores afirmaram possuir curso de graduação. De acordo com Amorim e Estaduto (2008, p. 22) "a escolaridade é o maior potencial de capital humano que se converte em gerenciamento, inovações de processos e de novas técnicas produtivas". Nota-se assim o quão importante a escolaridade se apresenta para o desenvolvimento da agroindústria familiar.

\subsection{Práticas de administração financeira nas agroindústrias familiares}

Para 94\% das famílias a instalação da agroindústria familiar gerou aumento na renda, o que representa 17 agroindústrias familiares das 18 que participaram da pesquisa. Apenas uma das famílias não obteve incremento na renda, e os motivos citados pelo seu administrador foram os altos custos de produção, assim como a inexistência de margem para lucro no volume de produção atual.

Nota-se assim que a agroindústria familiar apresenta alternativa promissora de acréscimo na renda das famílias. Gazolla e Pelegrini (2011, p. 381) enfatizam essa perspectiva ao declararem que "do ponto de vista econômico, a agroindustrialização da produção primária da agricultura familiar é uma alternativa viável e sustentável para as famílias rurais". Da mesma forma Lutke e Costa (2019) afirmam que muitas agroindústrias familiares vêm se formalizando, na busca de agregar valor à produção das famílias de agricultores e o acesso a novos mercados.

O aumento na renda familiar é o principal objetivo com a instalação da agroindústria familiar. E esse aumento na renda não se confirma apenas no município de ljuí/RS, pois Amorim e Staduto (2008), tendo como amostra 40 agroindústrias familiares no Oeste do Paraná, relatam que $95 \%$ das famílias obtiveram aumento na renda através do beneficiamento da produção agrícola ou pecuária. Wesz Júnior, Trentin e Filippi (2009) ressaltam que a elevação de renda, proporcionada pela instalação da agroindústria familiar, tem sido destacada em praticamente todos os estudos que se referem a estes empreendimentos. 
Nas propriedades rurais de ljuí/RS que possuem agroindústria familiar, esta atividade é a principal fonte de renda para 11 delas (61\%), enquanto para sete (39\%) essa atividade apenas complementa a renda familiar. Situação parecida foi encontrada por Niederle e Wesz Junior (2009) na região das Missões do Rio Grande do Sul, onde a agroindústria familiar é responsável por 54,6\% do total da renda das 143 propriedades rurais pesquisadas.

Em relação aos custos de produção, $61 \%$ dos gestores de agroindústrias familiares informaram que fazem o cálculo dos mesmos, enquanto 39\% informaram que não realizam nenhum cálculo para conhecer os custos. Através do cruzamento entre os dados da renda familiar proveniente da agroindústria familiar e da realização do cálculo de custos, foi possível notar que mesmo as agroindústrias que não realizam o cálculo de custos retiram deste empreendimento mais de $31 \%$ dos rendimentos familiares.

A única família que retira da agroindústria familiar menos de $31 \%$ de sua renda realiza o cálculo dos custos na atividade agroindustrial, o que pressupõem que a realização do cálculo de custos não é fator preponderante para a renda obtida através da agroindústria. Entretanto, sabe-se que o conhecimento de custos é fundamental para a área financeira, pois é um dos elementos que define o preço de venda.

Outra prática de administração financeira abordada foi o preço de venda. Cada agroindústria familiar apresenta algumas peculiaridades ao estabelecer o preço dos produtos. De maneira geral, o preço é estabelecido adicionando uma margem de lucro ao custo com matéria-prima e embalagens. Normalmente, a margem de lucro parte de $50 \%$ e pode chegar a $100 \%$ em relação ao valor dos custos.

Em alguns casos, o único fator levado em consideração para estipular o preço de venda é a observação do preço praticado pelos concorrentes. Na pesquisa de Hamann et al. (2010) foi exposto que não apenas algumas, mas sim a maior parte das agroindústrias familiares (59\%) define o preço de venda observando os preços praticados no mercado. Nas agroindústrias familiares de ljuí/RS, $83 \%$ dos respondentes consideram que o preço de venda praticado torna o produto competitivo no mercado.

Quanto ao capital de giro, 72\% das agroindústrias familiares possuem montante suficiente para manterem suas atividades. Como a matéria-prima geralmente é própria, o recebimento das vendas à vista e a mão de obra familiar, não há grande necessidade de capital de giro. Esse mesmo percentual de administradores (72\%) afirmou utilizar o capital próprio para realizar os investimentos na agroindústria familiar. Entre as outras formas de investimento, 39\% dos respondentes afirmaram recorrer aos financiamentos de instituições financeiras e $6 \%$ utilizam recursos públicos. Como poderia ser assinalada mais de uma alternativa, nota-se que algumas agroindústrias familiares fazem o uso de mais de uma forma de investimento.

De acordo com Crepaldi (2011), a contabilidade rural é uma das ferramentas administrativas menos utilizadas no Brasil, e muitas vezes é vista como uma técnica complexa e de baixo retorno. Esta situação foi percebida neste estudo, pois a contabilidade não é realizada em $67 \%$ das agroindústrias familiares pesquisadas. Entre as agroindústrias que fazem a contabilidade, as demonstrações contábeis mais utilizadas são a demonstração do resultado do exercício e a demonstração do fluxo de caixa.

O controle de contas a pagar é a ferramenta de administração financeira mais utilizada, sendo adotada por $61 \%$ das agroindústrias familiares, seguido pelo controle de contas a receber, utilizado por $50 \%$ e do controle de orçamento, utilizado por 22\%. O estudo de Zanella e Barrichello (2016) demonstrou que os administradores das agroindústrias familiares de Chapecó/SC utilizam o controle de contas a pagar como principal ferramenta de gestão financeira, representando $60 \%$ dos casos, o que se assemelha ao resultado encontrado no presente estudo. A forma de controle mais utilizada pelos administradores das agroindústrias familiares de ljuí/RS é a manual.

$\mathrm{Na}$ relação dos dados sobre a forma de controle e a escolaridade, verificou-se que o uso de planilhas de Excel e de software eletrônico para controle é feito por administradores de agroindústrias familiares que possuem ensino médio completo, ensino superior completo ou incompleto e curso de pós-graduação. $O$ controle manual é geralmente realizado por administradores com menor grau de escolaridade.

Os respondentes também foram indagados sobre as dificuldades na administração financeira. Entre as alternativas de resposta, a mais assinalada com $61 \%$ foi o pouco tempo disponível para trabalhar aspectos financeiros. A segunda alternativa mais assinalada foi o pouco conhecimento em administração financeira com $22 \%$. Para $11 \%$ das agroindústrias familiares de ljuí-RS não existem dificuldades na área financeira e $6 \%$ apontaram outras dificuldades nesta área. No estudo de Zanella e Barichello (2016), as maiores dificuldades apontadas na administração financeira das agroindústrias familiares também foram a falta de tempo e conhecimento na área financeira, representando $80 \%$ do total de respondentes.

Dos 18 administradores de agroindústria familiar, apenas 50\% afirmaram que fazem a separação das contas pessoais e da propriedade com as contas da agroindústria familiar. Conforme Crepaldi (2011), do ponto de vista organizacional, a agroindústria familiar deve estar ao máximo desvinculada da pessoa física, pois, dessa forma, ela será dotada de uma estrutura autônoma, responsável por todas as atividades que compõem o gerenciamento da administração financeira. Pelo exposto, nota-se a necessidade da separação das contas 
pessoais e da agroindústria familiar, porém sabe-se que a agricultura familiar apresenta a indissociabilidade das contas como uma característica marcante.

\subsection{Influência das variáveis ambientais na administração financeira das agroindústrias familiares}

Conforme Kotler e Keller (2013, p.10) “O macroambiente é formado por seis componentes: ambiente demográfico, ambiente econômico, ambiente sociocultural, ambiente natural, ambiente tecnológico e ambiente político-legal". As variáveis do macroambiente receberam alta importância pelos gestores das agroindústrias familiares, especialmente os ambientes político-legal, econômico e natural, mostrando que os fatores externos são relevantes para os administradores das agroindústrias familiares. Além da importância, este estudo tratou de relacionar cada ambiente com a administração financeira da agroindústria familiar, buscando demonstrar a influência das oportunidades e ameaças para este empreendimento.

No macroambiente a legislação, que compõem o ambiente político-legal, é fundamental para as agroindústrias familiares no tocante às licitações da merenda escolar, possibilitando aumento na renda. A Lei n० 11.947, de 16 de junho de 2009 determina que no mínimo 30\% do valor repassado para o Programa Nacional de Alimentação Escolar (PNAE) deve ser utilizado na compra de gêneros alimentícios diretamente da agricultura familiar e do empreendedor familiar rural ou de suas organizações (BRASIL, 2009).

O ambiente econômico tem relação com o ambiente sociocultural. Segundo extensionista da EMATER, os fatores culturais podem contribuir para agregar valor aos produtos da agroindústria familiar, uma vez que ljuí/RS é conhecida pela alcunha de "terra das culturas diversificadas" e, dessa forma, podem ser inseridos novos produtos ligados às origens étnicas dos membros de cada agroindústria familiar. Consiste em um desafio, pois segundo a EMATER (2019) o mix de produtos comercializados pelas agroindústrias familiares de ljuí/RS já é bastante diversificado e conta com panificados, derivados de cana-de-açúcar, massas, ovos, processamento de carne, derivados de leite, mel, peixes, moinho de trigo, doces e geleias.

O clima, componente do ambiente natural, é um fator preponderante para a obtenção de matériaprima. Portanto, a preocupação dos agricultores com o clima é compreensível, uma vez que ele "condiciona a maioria das explorações agropecuárias. Determina épocas de plantio, tratos culturais, colheitas, escolha de variedades e espécies vegetais e animais" (CREPALDI, 2011, p. 9). Também Wives e Kuhn (2018) relatam que a incerteza nas operações agrícolas é resultante da perecibilidade da produção e da existência de uma organização de colheitas sazonais, aliado à possibilidade de incidência de eventos climáticos desfavoráveis. Pelo exposto, percebe-se que o ambiente natural, através das condições climáticas, apresenta uma ameaça relevante para as agroindústrias familiares.

Em relação ao ambiente demográfico, a diminuição do êxodo rural é um dos benefícios com a instalação da agroindústria familiar. De acordo com Prezotto (2002), as agroindústrias familiares ajudam a manter as pessoas no campo, trabalhando e vivendo na agricultura, diminuindo as migrações desordenadas. Ainda em termos demográficos, o crescimento populacional representa novas oportunidades de negócio para as agroindústrias familiares, uma vez que ljuí é um município com potencial para atrair novos moradores, seja pela demanda de alunos do novo curso de Medicina da Unijuí, ou pela forte rede hospitalar que recentemente inaugurou o novo hospital Bom Pastor.

Quanto ao ambiente tecnológico, o mesmo apresenta a oportunidade para as agroindústrias familiares realizarem a gestão financeira de modo informatizado, através de planilhas eletrônicas para o controle de contas e fluxo de caixa, já que foi constatado que a maioria das agroindústrias familiares de ljuí/RS realiza o controle financeiro de forma manual. Prezotto (2002) destaca ainda que para determinar quais equipamentos e modelo tecnológico serão utilizados pela agroindústria familiar, tudo deve estar adequado à quantidade de produção prevista e a mão de obra disponível.

De acordo com Chiavenato (2003) o microambiente é o ambiente de operações das organizações e é constituído pelos fornecedores, clientes, concorrentes e entidades reguladoras. Os administradores das agroindústrias familiares pesquisadas também foram questionados sobre a importância das variáveis do microambiente.

Chama a atenção positivamente a alta importância atribuída aos clientes, sendo que $100 \%$ das agroindústrias familiares classificou-os como muito importantes. Os clientes têm papel relevante na administração financeira das agroindústrias familiares, uma vez que os mesmos são os responsáveis pela entrada dos recursos financeiros, e dessa forma são ligados diretamente à falta ou abundância destes recursos. Os concorrentes também podem influenciar a renda das agroindústrias familiares, já que a disputa pelos clientes pode reduzir as vendas e, por consequência, a receita da agroindústria.

Os produtos que os fornecedores entregam para as agroindústrias familiares compõem os custos, e dessa forma, compõem o preço de venda do produto final. Já as entidades reguladoras contribuem para a 
administração financeira, como o caso da EMATER que disponibiliza cursos e palestras na área de tributos, custos e também em outras áreas de gestão para a agroindústria familiar.

Conforme Silva (2005) o ambiente interno diz respeito à própria organização, pois consiste nos proprietários, empregados e administradores. Considerando o ambiente interno das agroindústrias familiares de ljuí/RS, os proprietários são os responsáveis pela instalação deste empreendimento, e também executam a função de administrador. Crepaldi (2011) ressalta que cabe ao administrador rural decidir sobre o quê, quanto e como produzir, além de controlar as ações após o início da atividade e avaliar os resultados alcançados.

Os administradores são ainda responsáveis pelas decisões que envolvem a administração financeira, como o estabelecimento dos preços, escolha de investimentos, entre outras. Como a mão de obra nas agroindústrias familiares usualmente é da própria família, a não necessidade de contratar empregados acaba gerando redução nos custos e potencializa a obtenção de renda com a atividade de agroindustrialização.

\section{CONSIDERAÇÕES FINAIS}

Este estudo teve o objetivo de investigar como são realizadas as práticas de administração financeira nas agroindústrias familiares do município de ljuí, no noroeste do Rio Grande do Sul. Inicialmente a pesquisa identificou o perfil das agroindústrias familiares, as quais estão instaladas em pequenas propriedades rurais e utilizam a mão de obra da família detentora do empreendimento. A pequena área da propriedade foi um dos motivos apontados para os pequenos agricultores apostarem na agroindustrialização, sendo esta uma oportunidade de obter renda superior àquela obtida pela simples venda das tradicionais commodities. Os administradores destas agroindústrias são, na maior parte dos casos, homens casados que possuem, como maior dificuldade na administração financeira, a falta de tempo para trabalhar as questões desta área.

O resultado econômico viabilizado pela agroindústria familiar de ljuí/RS é positivo, sendo que 17 das 18 famílias obtiveram aumento na renda após a instalação deste empreendimento. A mão de obra familiar e a matéria-prima própria são condições que reduzem o custo de produção da agroindústria familiar. Significa que a agricultura familiar, através da agroindustrialização, poderá contribuir com o desenvolvimento econômico e social, ao transformar os produtos agropecuários em alimentos saudáveis e de alto valor agregado. Portanto, a agroindústria familiar passa a ser uma alternativa para o incremento na renda, assim como um modelo de negócio com forte potencial para contribuir com a diminuição do êxodo rural e no processo de sucessão familiar, contribuindo desta forma na reprodução social dos agricultores familiares.

Além do acréscimo na renda familiar, outros aspectos da administração financeira das agroindústrias familiares foram notados. Os controles de contas a pagar e de receber são as ferramentas de administração financeira mais utilizadas, e a principal forma de controle é a manual. Para a grande maioria das agroindústrias familiares o capital de giro é suficiente, e alguns fatores como a mão de obra própria e o recebimento à vista das vendas justificam esta situação. A maior parte das agroindústrias familiares não realiza a contabilidade e $39 \%$ não realiza cálculo de custos, o que dificulta a administração financeira em aspectos importantes, como a formação de um preço de venda que assegure margem de lucro, sem comprometer a competitividade dos produtos. $O$ meio de recurso financeiro mais utilizado para investimentos é o capital próprio.

Pela análise ambiental das agroindústrias familiares de ljuí notou-se que o macroambiente, através do ambiente natural, constitui-se na principal ameaça, uma vez que as condições climáticas afetam a oferta das principais matérias-primas, o que gera reflexos no processo produtivo e no preço de venda dos produtos. $O$ ambiente tecnológico, por sua vez, apresenta a oportunidade de modernização nos controles financeiros, com o uso de planilhas digitais para o controle das contas e fluxo de caixa.

Considerando os elementos do microambiente, a única ameaça diz respeito aos concorrentes, pois podem surgir novas agroindústrias familiares que passam a disputar a preferência dos consumidores. Já os clientes recebem a devida importância e encontram nos produtos oferecidos pelas agroindústrias a qualidade e o sabor do interior de ljuí. As entidades reguladoras, principalmente a EMATER, oferecem suporte profissional, inclusive com orientações sobre tributos e outros aspectos financeiros. No ambiente interno, os proprietários da agroindústria familiar são os responsáveis pelas decisões que envolvem a administração financeira, como formação de preços e investimentos.

Sugere-se que pesquisas futuras busquem expandir os resultados encontrados neste estudo, analisando a área financeira das agroindústrias familiares de outras regiões do país. Da mesma forma, pesquisas que foquem a gestão das agroindústrias familiares são importantes. Poderá ser analisado quais as estratégias de marketing que as agroindústrias familiares utilizam. Além disso, estudos futuros podem analisar a viabilidade econômica das agroindústrias familiares em relação aos diferentes tipos de produtos comercializados. 


\section{REFERÊNCIAS}

AMORIM, L. S. B.; STADUTO, J. A. R. Desenvolvimento Territorial Rural: A Agroindústria Familiar no Oeste do Paraná. Revista de Economia Agrícola, São Paulo, v. 55, n. 1, p. 15-29, jan./jun. 2008.

BARDIN, L. Análise de conteúdo: edição revista e atualizada. São Paulo: Edições 70, 2011.

BRASIL. Lei No 11.326, de 24 de julho de 2006. Estabelece as diretrizes para a formulação da Política Nacional da Agricultura Familiar e Empreendimentos Familiares Rurais. Brasília-DF, Presidência da República, 2006. Disponível em: www.planalto.gov.br/ccivil_03/_Ato2004-2006/2006/Lei/L11326.htm. Acesso em: 10 jul. 2020.

BRASIL. Lei $\mathbf{n}^{\circ} \mathbf{1 1 . 9 4 7 / 2 0 0 9}$, de 16 de junho de 2009. Dispõe sobre o atendimento da alimentação escolar e do Programa Dinheiro Direto na Escola aos alunos da educação básica. Disponível em: www.planalto.gov.br/ccivil_03/_ato2007-2010/2009/lei/l11947.htm. Acesso em: 8 maio 2019.

CHIAVENATO, I. Introdução à Teoria Geral da administração. 7. ed. rev. e atual. Rio de Janeiro: Elsevier, 2003.

COOPER, D. R; SCHINDLER, P. S. Métodos de pesquisa em administração. Porto Alegre: Bookmann, 2011.

CREPALDI, S. A. Contabilidade rural: uma abordagem decisorial. 6. ed. São Paulo: Atlas, 2011.

EMATER. Unidade ljuí. Relatório das agroindústrias familiares de ljuí. ljuí, RS: Emater, 2019.

GAZOLLA, M.; PELEGRINI, G. As experiências familiares de agroindústrialização: uma estratégia de produção de novidades e de valor agregado. Ensaios FEE, Porto Alegre, v. 32, n. 2, p. 361-388, nov. 2011.

GIL, A. C. Métodos e técnicas de pesquisa social. 6. ed. São Paulo: Atlas, 2014.

GITMAN, L. J. Princípios de Administração Financeira. São Paulo: Pearson Prentice Hall, 2010.

GONZAGA, D. S. O. M.; CARTAXO, C. B. da C.; SILVA, F. de A. C.; PERE, R. T.; BAYMA, M. M. A. O perfil das agroindústrias familiares do Acre. O Rio Branco, Rio Branco, Opinião, 24 mar. 2016.

HAMANN, E. V.; PEREIRA, E. M.; BARRETO JUNIOR, E. A. M.; NASCIMENTO JÚNIOR, E. R. N.; SILVA, B. F. Custos para tomada de decisão para agroindústrias familiares da região de Planaltina-DF. In: CONGRESSO BRASILEIRO DE CUSTOS, 17., 2020, Belo Horizonte. Anais [...]. Belo Horizonte: Associação Brasileira de Custos, 2010.

KARNOPP, Erica et al. AGROINDÚSTRIAS FAMILIARES NO SUL DO BRASIL: UM ESTUDO COMPARATIVO. Revista Brasileira de Gestão e Desenvolvimento Regional, [S.I.], v. 15, n. 7, dez. 2019.

KAUTSKY, K. A Questão Agrária. 3. ed. São Paulo: Proposta Editorial, 1980.

KOTLER, P.; KELLER, K. L. Administração de marketing. 14. ed. São Paulo: Pearson Education do Brasil, 2013.

LÊNIN, W. I. O Desenvolvimento do Capitalismo na Rússia. São Paulo: Ed. Abril Cultural,1982.

LUTKE, V.; DA COSTA, C. Agroindústrias familiares, mercados institucionais e empoderamento das mulheres. Campo - Território: Revista de Geografia Agrária, v. 14, n. 32, abr., 2 set. 2019.

MALHOTRA, N. K. Pesquisa de Marketing: foco na decisão. São Paulo: Pearson Education do Brasil, 2011.

MINAYO, M. C. de S.; DESLANDES, S. F.; GOMES, R. (org.) Pesquisa Social: teoria, método e criatividade. 30. ed. Rio de Janeiro: Vozes, 2011. 
MIOR, L. C. Agricultores familiares, agroindústrias e redes de desenvolvimento rural. Chapecó: Unochapecó, Editora Argos, 2005, 338p.

MIOR, L. C. Agricultura familiar, agroindústria e desenvolvimento territorial. In: COLÓQUIO INTERNACIONAL DE DESENVOLVIMENTO RURAL SUSTENTÁVEL, 22., 2007, Florianópolis. Anais [...]. Florianópolis: UFSC, 2007.

NIEDERLE, P. A; WESZ JUNIOR, V. J. A agroindústria familiar na região Missões: construção de autonomia e diversificação dos meios de vida. Redes, Santa Cruz do Sul, v. 14, n. 3, p. 75-102, dez. 2009.

ORSOLIN, J. Gestão da comercialização na agroindústria familiar. Rev. Administração, Frederico Westphalen, v. 5, n. 8, p. 15-37, 2006.

PREZOTTO, L. L. Uma concepção de agroindústria rural de pequeno porte. Revista de Ciências Humanas, Florianópolis: EDUFSC, n.31, p. 133-153, abr. 2002.

POTRICH, R.; GRZYBOVSKI, D; TOEBE, C. S. Sustentabilidade nas pequenas propriedades rurais: um estudo exploratório sobre a percepção do agricultor. Estudos Sociedade e Agricultura, v. 25, n. 1, p. 208-228, fev. 2017.

PROFETA, G. A.; FERREIRA, G. S.; SANTOS, E. V. M.; NEY, V. DA S. P. Pluriatividade e economia criativa. Campo Território: Revista de Geografia Agrária, v. 14, n. 34, dez., 22 abr. 2020.

RIO GRANDE DO SUL (2012a). Lei $\mathbf{n}^{\circ}$ 13.921, de 17 de janeiro de 2012. Institui a Política Estadual de Agroindústria Familiar no Estado do Rio Grande do Sul. Diário Oficial do Rio Grande do Sul, 18 de janeiro de 2012. Disponível em:

www.al.rs.gov.br/legis/M010/M0100099.ASP?Hid_Tipo=TEXTO\&Hid_TodasNormas=57295\&hTexto=\&Hid_ID Norma $=57295$. Acesso em: 25 nov. 2019.

RIO GRANDE DO SUL (2012b). Decreto No 49.341, de 05 de julho de 2012. Cria o Programa de Agroindústria Familiar do Estado do Rio Grande do Sul, institui o selo de marca de certificação "Sabor Gaúcho" e dá outras providências. Publicado no DOE no 130, de 06 de julho de 2012. Disponível em https://leisestaduais.com.br/rs/decreto-n-49341-2012-rio-grande-do-sul-cria-o-programa-de-agroindustriafamiliar-do-estado-do-rio-grande-do-sul-institui-o-selo-de-marca-de-certificacao-sabor-gaucho-e-da-outrasprovidencias. Acesso em: 25 nov. 2019.

SILVA, R. O. da. Teorias da Administração. São Paulo: Pearson Makron Books, 2005.

VERGARA, S. C. Projetos e Relatórios de Pesquisa em Administração. São Paulo: Atlas, 2009.

WESZ JÚNIOR, V. J.; TRENTIN, I. C. L. Agroindústrias Familiares e o Desenvolvimento das Economias Locais. Redes, Santa Cruz do Sul, v. 10, n. 2, p. 249-265, maio/ago. 2005.

WESZ JÚNIOR, V. J.; TRENTIN, I. C. L.; FILIPPI, E. E. Os reflexos das agroindústrias familiares para o desenvolvimento das áreas rurais no Sul do Brasil. Cuadernos de Desarrollo Rural, v. 6, n. 63, p. 59-85, Bogotá, jul./dez. 2009.

WIVES, D. G.; KUHN, D. D. Gestão e planejamento de agroindústrias familiares. Porto Alegre: Editora da UFRGS, 2018. $104 \mathrm{p}$.

ZANELLA, F. S.; BARICHELLO, R. Gestão financeira na agricultura familiar: um estudo de casos nas micros e pequenas empresas ligadas a Cooperativa Alternativa de Chapecó-SC. Chapecó-SC: UNIEDU, 2016.

ZIGER, V. 0 Crédito Rural e a Agricultura Familiar: desafios, estratégias e perspectivas. PublicaCresol, 2013. Disponível em: http://www.cresol.com.br/site/upload/downloads/183.pdf. Acesso em: 28 nov. 2019. 